\title{
INCLUSÃO DIGITAL DE PROFESSORES DA REDE PÚBLICA DO SERIDÓ
}

Maria Jane de Queiroz ${ }^{1}$

Wagner Luiz Alves da Silva ${ }^{1}$

Maria Elenir Nobre P. Ribeiro ${ }^{1}$

\section{RESUMO}

O projeto "NTICs na educação: O uso do Linux Educacional no Ensino", realizado pelo IFRN - Campus Currais Novos, tem como objetivo promover a inclusão digital dos docentes de escolas públicas municipais e estaduais da cidade de Currais Novos e regiões circunvizinhas por meio da realização de um curso de capacitação em Linux Educacional. Além da capacitação de docentes, o projeto atingirá consequentemente os alunos das escolas públicas que serão ensinados pelos professores capacitados sobre o uso das ferramentas disponíveis nesse sistema operacional. Outra consequência do projeto será o uso adequado dos laboratórios disponibilizados pelo MEC através do PROINFO, evitando-se a ociosidade dos recursos tecnológicos existentes na escola. Assim, o projeto pretende atingir, de forma direta e indireta, toda a comunidade local envolvida com questões de ensinoaprendizagem, utilizando-se as novas tecnologias de informação e comunicação.

Palavras-chave: Tecnologia. Ensino. Linux Educacional.

\section{INTRODUÇÃO}

A portaria no 522, de 9 de abril de 1997 instituiu a criação do PROINFO (Programa Nacional de Informática na Educação). Segundo essa portaria, o programa objetiva "disseminar o uso pedagógico das tecnologias de informática e telecomunicações nas escolas públicas de ensino fundamental e médio pertencentes às redes estadual e municipal". Para isso, o MEC (Ministério da Educação) realiza a compra, distribuição e instalação de laboratórios de informática em escolas públicas de educação básica.
Para participar do programa, a escola interessada deve realizar um cadastro junto ao MEC e oferecer a infraestrutura básica para o recebimento dos computadores. Tais computadores vêm com o sistema operacional Linux Educacional, versão 3.0, instalado. Esse sistema possui diversos aplicativos voltados para o ensino de disciplinas básicas como Português, Matemática, Ciências, Geografia, dentre outras e possibilita a adição de objetos de aprendizagem criados pelos próprios usuários ou adquiridos via download no Portal do Professor.

Desde a implantação do programa, já são mais de 34 mil escolas urbanas e 22 mil escolas 
rurais atendidas (CGU, 2013). No entanto, muitos professores ainda desconhecem o que é Linux e a aplicação das ferramentas disponíveis nesse sistema para o ensino. Além disso, o PROINFO não prevê, em sua portaria e em seu termo de adesão, a realização de cursos de capacitação para professores do ensino público.

Assim, para preencher essa lacuna no conhecimento das NTICs pelos professores do ensino público do município de Currais Novos e regiões circunvizinhas, este projeto promoverá a inclusão digital desses agentes da educação por meio da realização de um curso de capacitação em Linux Educacional, a fim de possibilitar o uso e aplicação corretos das NTICs no ensino.

Dessa forma, o principal objetivo do curso é promover a inclusão digital dos professores do ensino público do município de Currais Novos e regiões circunvizinhas, incentivando o uso das novas tecnologias da informação e comunicação na prática pedagógica por meio da orientação dos docentes com relação ao uso adequado dos objetos de aprendizagem disponíveis no sistema operacional Linux Educacional.

\section{METODOLOGIA}

A metodologia do curso consistirá em aulas expositivas e práticas, realizadas em laboratórios de informática contendo o sistema operacional Linux Educacional instalado. Ao final do curso, os cursistas deverão projetar uma aula em sua área de atuação, utilizando os recursos e ferramentas vistos durante o período de capacitação. A pontualidade, assiduidade e interesse na realização das atividades também serão contabilizados como forma de avaliação parcial no curso.

Para acompanhamento da evolução dos participantes do curso no uso das novas tecnolo- gias da informação e comunicação, serão realizados questionários no início e ao final do curso de capacitação, além de atividades propostas pelos instrutores no decorrer do projeto.

Para acompanhamento do projeto, deverão ser realizados relatórios semanais contendo a descrição das atividades realizadas pelos proponentes do projeto e os resultados obtidos a partir dessas atividades.

\section{RESULTADOS}

A primeira fase do projeto já foi concluída, sendo composta pelo planejamento, onde foram definidos o período e duração em termos de meses, horários das aulas e dias de curso.

A segunda fase também já foi realizada, sendo constituída pela elaboração do material de divulgação e do material didático para as aulas. Nesta fase, foi elaborada uma logomarca para o projeto (Figura 1), a qual foi utilizada no material de divulgação e será utilizada também no kit didático que está em fase de conclusão e nas camisetas para os membros do projeto, a fim de identificá-los.

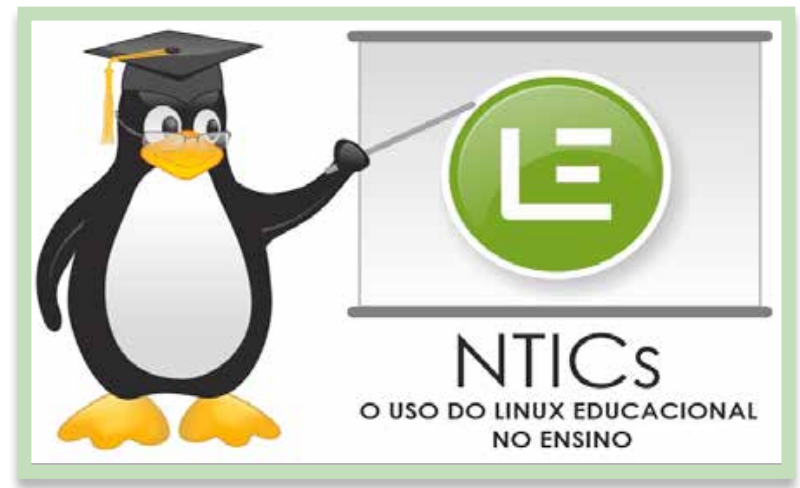

Figura 1: logomarca do projeto.

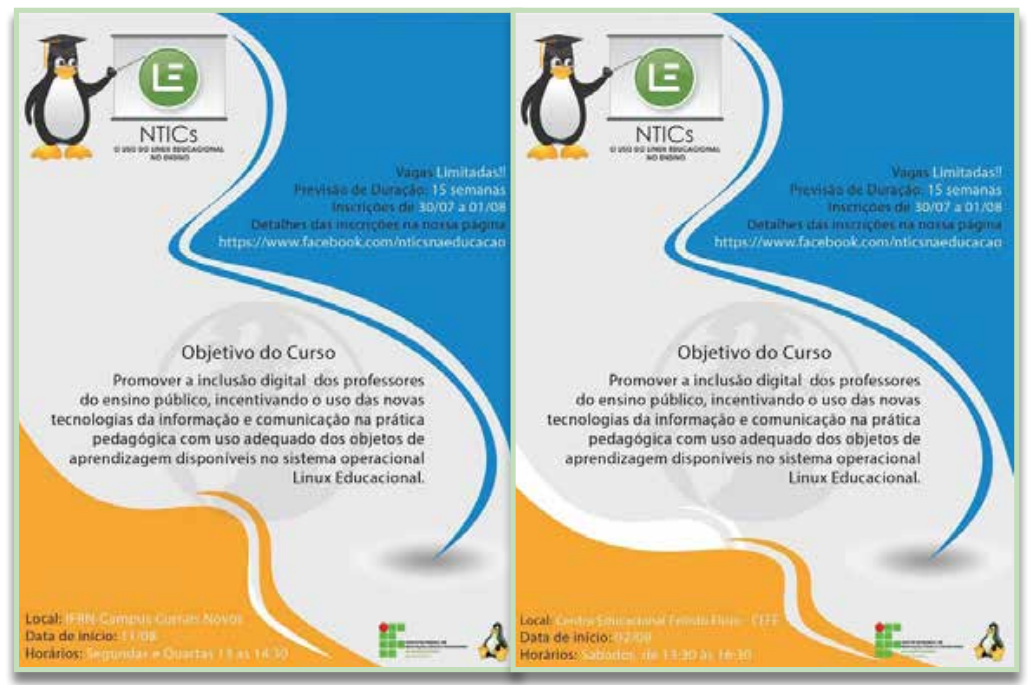

Figura 2: material de divulgação em Currais Novos e Jardim do Seridó 
O kit didático, citado anteriormente, será entregue a cada cursista e será composto por um DVD com a imagem da distribuição Linux Educacional, para que o cursista possa instalar esse sistema operacional em seu computador pessoal e ter autonomia nos estudos; uma apostila com o conteúdo do curso, bloquinho de papel e caneta.

A terceira fase foi constituída pela divulgação do projeto em três Escolas Públicas de Ensino Fundamental e Médio de Currais Novos: Capitão Mor Galvão, Instituto Vivaldo Pereira e Tristão de Barros, além de uma escola em Jardim do Seridó (Centro Educacional Felinto Elísio). A divulgação foi feita com a apresentação da proposta para a instalação do sistema operacional Linux Educacional.

Como o projeto encontra-se em sua fase inicial, esperam-se como resultados de longo prazo que o mesmo atinja o maior número possível de pessoas (de forma direta, com a capacitação de professores, e de forma indireta, com o repasse de conhecimentos dos professores capacitados a seus alunos) e que o objetivo principal, que é a inclusão digital dos docentes de escolas públicas da rede municipal e estadual da região do Seridó do Rio Grande do Norte, seja alcançado.

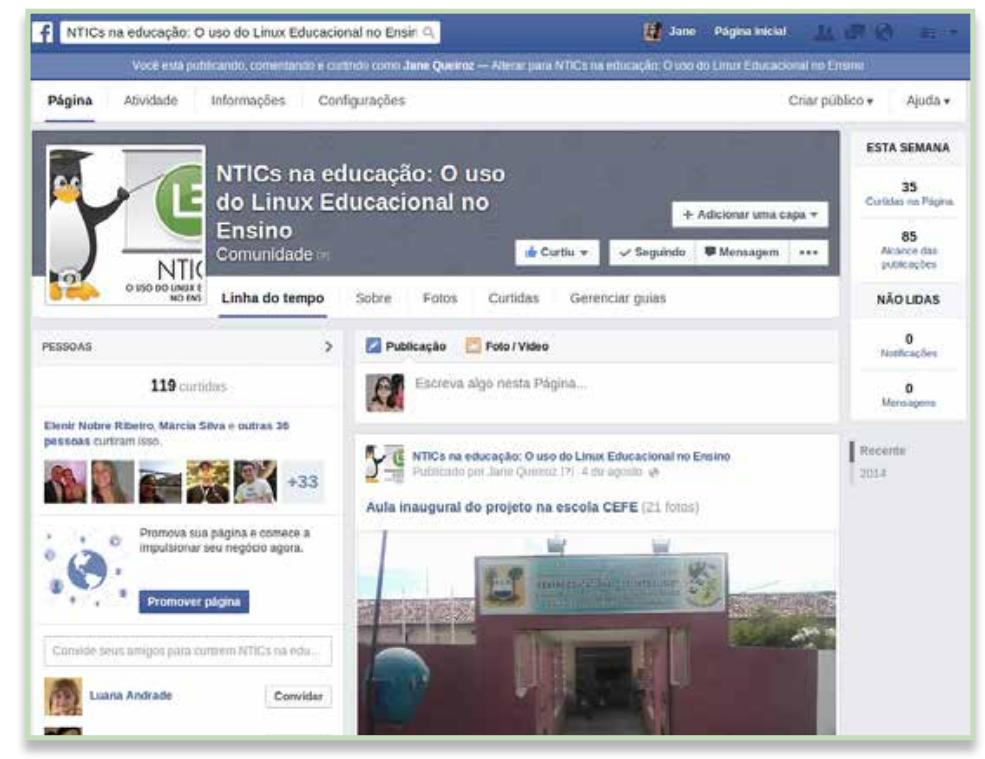

Figura 3: página do projeto no Facebook.

do projeto aos professores das referidas escolas e a afixação de cartazes com informações sobre inscrição, período e local de curso (Figura 2).

Além da visita às escolas, foi utilizada também como meio de divulgação uma comunidade criada na rede social Facebook, muito utilizada pelo público-alvo, contendo links para inscrições, formulários, informações sobre o curso e fotos do projeto, conforme Figura 3.

Considerando-se o objetivo inicial, de estender o projeto às regiões vizinhas a Currais Novos, o curso está sendo ofertado também em Jardim do Seridó, na escola CEFE (Centro Educacional Felinto Elísio), cujas aulas acontecem aos sábados para atender à disponibilidade dos cursistas.

$\mathrm{Na}$ cidade de Currais Novos, as aulas acontecerão também aos sábados, no laboratório de informática do IFRN, utilizando-se máquinas virtuais criadas com o software Virtual Box

\section{REFERÊNCIAS}

BRASIL. Ministério da Educação e do Desporto. Criação do Programa Nacional de Informática na Educação - Prolnfo. Portaria no 522, de 9 de abril de 1997.

CONTROLADORIA-GERAL DA UNIÃO - CGU. Relatório de Avaliação da Execução de Programas de Governo no 16: Infraestrutura de Tecnologia da Informação para a Educação Básica Pública (Proinfo). Brasília, jan. 2013, p. 7.

MINISTÉRIO DA EDUCAÇÃO - MEC. Portal do Professor. Disponível em: <http:// portaldoprofessor.mec.gov.br/index.html>. Acesso em: 30 jul. 2014.

PROINFO. Sobre o Linux Educacional. Disponível em: <http://webeduc.mec.gov.br/ linuxeducacional/pagns/sobre_le.php $>$. Acesso em: 08 ago. 2014. 